\section{Estratégias homeopáticas: a Liga Homeopática do Rio Grande do Sul nos anos 1940-1950}

\section{Homeopathic strategies: the Homeopathic League of Rio Grande do Sul in the 1940s and 1950s}

WEBER, Beatriz Teixeira. Estratégias homeopáticas: a Liga Homeopática do Rio Grande do Sul nos anos 19401950. História, Ciências, Saúde Manguinhos, Rio de Janeiro, v.18, n.2, abr.-jun. 2011, p.291-302.

\section{Resumo}

Após 1930, vários espaços foram usados pelos homeopatas para divulgação de sua proposta, apesar de o período ser considerado de declínio de sua inserção acadêmica. É o caso das atividades desenvolvidas pela Liga Homeopática do Rio Grande do Sul, fundada em 1941, que publicou uma revista até os anos 1970, fundou três dispensários para atendimento gratuito da população em Porto Alegre e manteve atuante um grupo de homeopatas, inserido na discussão política que procurava difundir e ampliar a prática homeopática. A análise do Boletim de Homeopatia, editado pela Liga, permite considerar as estratégias de inserção dos homeopatas na capital do Rio Grande do Sul.

Palavras-chave: história da homeopatia; Liga Homeopática; divulgação; boletim homeopático; Brasil.

\section{Abstract}

Although the period following 1930 has been considered an era in which homeopathy lost ground within academia, homeopaths nevertheless were advocating for their proposals in a variety of spaces. One such instance was represented by the Homeopathic League of Rio Grande do Sul, founded in 1941, which published a journal until the 1970s, set up three free dispensaries to serve the population in Porto Alegre, and played an active role in political discussions through a group of homeopaths who endeavored to disseminate and expand homeopathic practice. An analysis of the League's Boletim de Homeopatia provides insight into homeopaths' strategies for expanding their role in Porto Alegre, capital of Rio Grande do Sul.

Keywords: history of homeopathy; Homeopathic League; dissemination; homeopathic bulletin; Brazil. 
$\mathrm{A}^{\mathrm{b}}$ bibliografia referente à homeopatia no Brasil considera que o período posterior a 1930 é de declínio acadêmico até a década de 1970, quando ocorre sua retomada, com reconhecimento social, até 1990. A partir dos anos 1930, observa-se expansão das grandes indústrias farmacêuticas e do modelo de atenção médico-hospitalar, o que, provavelmente, diminuiu a inserção social que a homeopatia detinha (Luz, 1996, p.39-45, 217-334).

Apesar do declínio acadêmico, outras atividades de organização foram muito importantes na divulgação da homeopatia no Brasil no início do século XX. A primeira edição do Congresso Brasileiro de Homeopatia ocorreu em 1926, no Rio de Janeiro, reunindo muitos trabalhos (Meirelles, 1991, p.9). Nessa época o Brasil era considerado o principal país do continente americano em que se desenvolviam os ensinamentos e a prática da doutrina hahnemanniana. Nos anos 1920, a homeopatia despontava como ameaça à alopatia que, por sua vez, se empenhava em desacreditar a teoria homeopática, dizendo-a um apanhado de hipóteses sem fundamentação científica e uma terapêutica sem efeito (Bertolli Filho, 1988, p.5). Houve nessa década um sensível avanço de atividades políticas e práticas diversificadas - questionamento da proposta republicana, que não atendera aos interesses da população -, resultando na Revolução de 1930. Várias dessas propostas ameaçaram a ordem vigente, como, por exemplo, a homeopatia e, para citar apenas movimentos ligados a práticas religiosas, a expansão do espiritismo, o surgimento da umbanda, o movimento unionista da Igreja católica. Dadas a constatação das desigualdades e a manutenção das diferenças após a Abolição e a República, configurando uma 'modernização sem mudanças', vários grupos se anteciparam às esperadas respostas oficiais do Estado e constituíram estratégias de defesa de suas crenças e tradições. O catolicismo deixa de ser a religião oficial e, ao longo do século XIX, desagrega-se progressivamente - reforça-se assim a proliferação de ampla diversidade de outras práticas (Gertz, 2002, p.89-123).

A alopatia preocupou-se em ser porta-voz das diretrizes do Estado varguista, fruto da Revolução de 1930, propondo-se normatizar e responsabilizar os indivíduos por seus próprios males, o que constituiu parcela do 'projeto nacional' autoritário, com base em postura eugenista (Bertolli Filho, 1988, p.5, 12). Visando impor-se ao poder do Estado, os homeopatas optaram pela organização da categoria, criando associações de âmbito regional e promovendo encontros de caráter nacional, empenhados em institucionalizar a homeopatia e apresentá-la como alternativa à alopatia. A principal preocupação dos homeopatas foi fazer frente à avalancha autoritária que procurava possibilidades para a 'unificação' nacional.

Em 1932 foi criada a Liga Homeopática Brasileira, que teve duração efêmera, e, em 1936, a Associação Paulista de Homeopatia (Bertolli Filho, 1988, p.5; Meirelles, 1991, p.9). Em 1945, com a finalidade de estimular a divulgação dos princípios homeopáticos no Brasil, foi fundada a Federação Brasileira de Homeopatia, com sede no Rio de Janeiro.

Antes disso, porém, em 17 de abril de 1941, no Rio Grande do Sul, foi fundada oficialmente a Liga Homeopática do estado - objeto deste artigo -, iniciativa do doutor David Castro, nascido em Recife em 1915, formado em medicina na Bahia e em homeopatia no Rio de Janeiro, que se instalara no Rio Grande do Sul por recomendação do doutor José Emygdio Galhardo. A diretoria provisória então nomeada assim se compunha: presidente, doutor Sabino Menna Barreto; vice-presidente, doutor Alfredo Ludwig; primeiro tesoureiro, Luiz G. Klein; orador, doutor Souza Lobo; e diretor de propaganda, doutor David Castro, 
que permaneceu no cargo até maio de 1955, quando se transferiu para o Rio de Janeiro (Martins, s.d.).

O órgão oficial dessa Liga foi o Boletim de Homeopatia, publicado regularmente de 1941 a 1963, totalizando 186 números. Segundo o material de divulgação atual da Liga, em 1944 passou a chamar-se Revista de Homeopatia (Figura 1). Este texto analisa a proposta de divulgação da homeopatia de 1941 a 1955, através das atividades da Liga, e, principalmente, do material publicado em seu órgão oficial. O recorte refere-se ao período em que David Castro atuou como seu diretor de divulgação.

\section{REVISTA DE HOMEOPATIA \\ ORGXO OFICIR工 DA LIGA HOMEOPATICA DO RIO GRANDE DO SUL PUBLICAÇ XO BIMEBTRAL \\ DIRETOR RESPONSAVEL: DR. DAVID CASTRO \\ SECRETARIO: IVEBCIO PACHECO

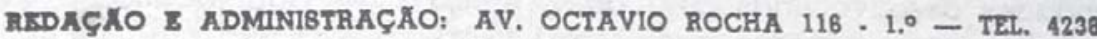

\begin{tabular}{l||l|l|}
\hline Numero 1 & Porto Alegre, Norembro-Dezembro 1912 & A N O I \\
\hline
\end{tabular}

\section{SUMARIO}

Kpresentação

O que é a Homeopatia - Dr. Nery Gonçalves

Gotas Homeopáticas

Campanha pró novos socios - Dr. David Castro ............ \& 8

Dispensário Homeopático $\ldots \ldots \ldots \ldots \ldots \ldots \ldots \ldots \ldots \ldots \ldots \ldots \ldots \ldots$

Palestras Radiofônicas $\ldots \ldots \ldots \ldots \ldots \ldots \ldots \ldots \ldots \ldots \ldots \ldots \ldots$

Um benfeitor da Llga Homeopática .................. 7

Homenagem aos Homeopatas do Estado - Caldre Fião .... 14

Livros sobre Homsopatia $\ldots \ldots \ldots \ldots \ldots \ldots \ldots \ldots \ldots \ldots \ldots \ldots \ldots \ldots$ is

Plulas Coluna Homeopáticas $\ldots \ldots \ldots \ldots \ldots \ldots \ldots \ldots \ldots \ldots, 16$

Figura 1: Sumário do primeiro número da Revista de Homeopatia, que sucedeu o Boletim de Homeopatia como órgão oficial de divulgação da Liga Homeopática do Rio Grande do Sul 
As fontes utilizadas foram localizadas sobretudo na Biblioteca do Instituto Hahnemanniano do Brasil, no Rio de Janeiro, que abriga coleção praticamente completa do Boletim/ Revista de Homeopatia. Os números que ali faltam foram consultados na coleção da Liga Homeopática do Rio Grande do Sul, que possui exemplares de todas as edições. Na avaliação da proposta consideram-se os limites próprios a um órgão de divulgação oficial editado pelos proponentes; o principal objetivo é analisar as estratégias que em suas páginas eles defenderam.

Além da descrição das atividades da Liga ${ }^{1}$, o texto analisa os discursos de defesa da prática homeopática proferidos principalmente por David Castro, como estratégia para a ampliação das atividades homeopáticas no Brasil, mas de modo especial no Rio Grande do Sul.

\section{A Liga Homeopática do Rio Grande do Sul}

A proposta da Liga no Rio Grande do Sul era divulgar os princípios da homeopatia através de várias atividades, congregando seus adeptos. Os membros que assumiram a diretoria da Liga, em substituição aos nomeados em caráter provisório, mantiveram-se como responsáveis pela instituição durante longo período. O diretor passou a ser o desembargador Nésio de Almeida, tendo como vice José de Oliveira Freitas. Incansáveis defensores da proposta, os mesmos indivíduos realizavam as atividades de divulgação em várias instâncias. O Boletim de Homeopatia publicava regularmente lista de todos os envolvidos na contracapa, incluindo um conselho deliberativo com 11 membros, sócios honorários e sócios benfeitores, como os Irmãos Bernardi \& Cia., que doaram o terreno para a construção do primeiro dispensário; a Rádio Sociedade Farroupilha, que criou programa de rádio semanal sobre homeopatia; e o Diário de Notícias, jornal de Porto Alegre, que manteve coluna semanal intitulada "Pílula Homeopática", em que se divulgavam frases ou casos de pessoas que se aproximaram da homeopatia ou com seus recursos se curaram; essas matérias eram em parte reproduzidas pela Rádio Farroupilha. Havia também os sócios cooperadores, como Luiz G. Klein \& Cia., que doavam parte da medicação utilizada pelos dispensários e patrocinavam as palestras radiofônicas, Arthur Basbaum, Laboratório de Homeopatia Dr. Alberto Seabra Ltda. e a Farmácia e Laboratório Homeopático Ltda. A partir do segundo número do Boletim, aparece na contracapa relação nominal dos sócios da Liga, que em 1942 eram 126. A estratégia visando angariar apoio para a homeopatia e divulgar sua proposta era bastante importante não só pelo aspecto quantitativo, mas também pela notória autoridade de numerosos adeptos.

A partir da doação de terreno na avenida Assis Brasil (Passo da Mangueira) pelos irmãos Bernardi, iniciou-se a construção do primeiro dispensário homeopático - cuja proposta era oferecer consultas gratuitas - com doações da Caixa Econômica do Rio Grande do Sul, Banco da Província, Banco do Rio Grande do Sul, Banco do Comércio e das Lojas Brasileiras S.A.; o maior montante, entretanto, consistiu de empréstimo da Caixa Econômica Federal, a ser pago em sessenta prestações. Todos os dados são minuciosamente descritos no Boletim, procurando mostrar transparência no acesso aos recursos e em seu uso, e divulgando as informações financeiras dos dispensários e da Liga. A distribuição do primeiro número do 
Boletim foi feita durante a inauguração do primeiro dispensário, em 7 de novembro de 1942, transmitida pela Rádio Farroupilha. Todos esses procedimentos são descritos no segundo número do Boletim, agradecendo também aos doadores voluntários que se sensibilizaram com a proposta de atendimento do dispensário, incluindo os que colaboraram com pequenos valores, com 1.800 tijolos e com a placa comemorativa colocada à frente do prédio.

A Liga manteve outros dois dispensários homeopáticos com atendimento gratuito, um na rua Sertório (bairro Navegantes), em terreno doado pelo dono das indústrias A.J. Renner, inaugurado em 14 de outubro de 1945, e outro na avenida Getúlio Vargas (bairro Menino Deus), inaugurado em 2 de maio de 1952, local em que hoje se situa a sede da Liga. Esses dispensários, que em 1977 ainda funcionavam (Boletim..., 1977), atendiam regularmente considerável número de pessoas, conforme os dados apresentados pela revista. Em 1948, por exemplo, os dois dispensários então existentes (Boletim..., 1949) receberam 5.456 pessoas, sendo 3.259 crianças e 2.197 adultos. Cabe observar que a população de Porto Alegre, em 1950, era de 394.151 habitantes, 321.907 dos quais na área urbana (FEE, 1981).

A atividade dos dispensários era a principal propaganda prática da Liga. Todos os dispensários foram considerados de utilidade pública pelos governos municipal, estadual e federal. Na exposição dos motivos que justificam a adoção desses órgãos como de utilidade pública, todos os pareceristas destacam os relevantes serviços prestados à ciência e à sociedade pela Liga e pelos dispensários, ressaltando elogios ao atendimento e, especialmente, à figura do doutor David Castro. Por isso, receberam auxílio em dinheiro do governo do estado para a manutenção das atividades, em 1951 e 1952, e em 1954 da Prefeitura de Porto Alegre, que também doou o terreno para a construção do terceiro dispensário. Todos esses apoios e o respaldo das várias instituições estaduais indicam que conseguiram destacar a importância de suas atividades, tendo sido, portanto, eficientes as estratégias adotadas.

Uma das principais estratégias consistiu em palestras radiofônicas semanais na Rádio Farroupilha, desde junho de 1941. Patrocinadas por Luiz G. Klein \& Cia. e proferidas por David Castro, abordavam diversos assuntos que incluíam esclarecimentos sobre os princípios da homeopatia, demonstrando qual seria seu papel como medicina de real valor, humana e do futuro (Boletim..., 1950, p.17). A partir de outubro daquele ano a Rádio Farroupilha também transmitia - às quintas-feiras, de 19:45h em diante - a leitura de "Pílulas Homeopáticas", texto publicado aos domingos no jornal Diário de Notícias; na mídia escrita havia, além dessa, a "Coluna Homeopática" de propaganda quinzenal, aos domingos, no jornal Correio do Povo, patrocinada igualmente pela empresa Luiz G. Klein \& Cia.

Segundo Bertolli Filho (1988, p.5), a estratégia de divulgação dos princípios de Hahnemann através de conferências e palestras transmitidas por rádio foi usada na década de 1930 pelos homeopatas em São Paulo e no Rio de Janeiro, o que, entretanto, os vulgarizou, ocasionando sua condenação e transformação em chacota por parte dos alopatas mais radicais, uma vez que foram nivelados às drogas populares, também anunciadas pelo rádio, como xaropes, anticaspas, sabonetes e cremes de beleza. Apesar dessa desqualificação, os homeopatas continuaram a insistir nesse formato como estratégia própria para a ampliação do conhecimento de sua teoria e suas atividades. O rádio era importante meio moderno de divulgação, que permitia a recepção das informações por número cada vez 
maior de pessoas, apesar de o papel desse meio de comunicação para fins educativos no campo da saúde pública ainda estar por merecer a atenção dos pesquisadores (Rodrigues, Vasconcellos, 2007).

No caso do Rio Grande do Sul, a Rádio Sociedade Farroupilha, utilizada para divulgação, marca a organização de espetáculo radiofônico, que se consolidou na década de 1940, assumindo proposta de organização comercial da rádio. De 1935 a 1943, a Farroupilha permaneceu sob controle da família Flores da Cunha, também proprietária da Empresa Jornalística Rio-Grandense, que editava os diários Jornal da Manhã e Jornal da Noite. O general José Antônio Flores da Cunha governou o estado de 1930 a 1937, parte como interventor federal nomeado por Getúlio Vargas e parte como governador. Divergências entre ele e Vargas provocaram sua renúncia em 1937, pouco antes da decretação do Estado Novo. A rádio, então, enfrentou dificuldades que levaram a sua venda, em 1943, para os Diários e Emissoras Associados, responsáveis pela modernização de sua linha de atuação, com programas de auditório, radionovelas e humorísticos que a popularizam a partir de então (Ferraretto, 2002, p.18, 114). A radiodifusão teve importante papel no estado na divulgação de informações novas e sua popularização para público cada vez mais amplo na década de 1950. Os homeopatas gaúchos aproveitaram então esse novo e importante veículo de comunicação para afirmar e difundir suas propostas.

Outro relevante aspecto de difusão da Liga dizia respeito à publicação de livros sobre homeopatia, sendo os recursos arrecadados encaminhados para a manutenção das demais atividades. Visando ampliar a divulgação dos postulados defendidos, a Biblioteca da Liga Homeopática do Rio Grande do Sul publicou cinco volumes na gestão de David Castro na Diretoria de Propaganda, de 1941 a 1955, além de títulos de renomados homeopatas, como Alberto Seabra e o próprio David Castro.

A Liga inaugurou em 1943 o primeiro monumento à homeopatia em praça pública na América do Sul, no Parque Farroupilha - a herma de Hahnemann, comemorando o centenário de sua morte. A realização de eventos em Porto Alegre também foi importante instrumento de divulgação. Em 1944, o 1ํㅡㄹ Congresso Sul-Americano de Homeopatia, presidido por David Castro, contou com a presença de médicos argentinos, uruguaios e do Centro do país, com apoio do governo do estado. Em 1952, realizou-se a quarta edição do Congresso Brasileiro de Homeopatia, também sob a presidência do doutor David Castro. Nesse congresso, oficializado pelo governo do estado, houve o lançamento de selo comemorativo do centésimo aniversário do doutor Licínio Cardoso, inaugurou-se o terceiro dispensário da Liga e outra herma no Parque Farroupilha, em memória ao doutor Licínio, gaúcho de Lavras do Sul, fundador do Hospital e da Faculdade Hahnemanniana, ambos no Rio de Janeiro.

Diversas foram as atividades desenvolvidas pela Liga no empenho de manter-se como veículo de divulgação da homeopatia no estado, articulando as várias ações como estratégico conjunto de colocação de seus interesses. Essas estratégias foram consideradas necessárias para fazer a homeopatia tornar-se prática disseminada socialmente no futuro, resultado do esforço de todos os praticantes. 


\section{Estratégias e justificativas}

No caso do Rio Grande do Sul, o principal estrategista homeopático e mentor de divulgação foi David Castro, que, como diretor de propaganda da Liga Homeopática, foi também o maior responsável pelo teor das publicações no Boletim de Homeopatia até 1955. A maioria dos textos publicados era de sua autoria ou a partir de suas informações.

David Castro nasceu em Recife e fez a primeira parte dos seus estudos na Bahia, mas formou-se pela Escola de Medicina do Rio de Janeiro, ali atuando posteriormente como professor de clínica médica homeopática, ramo da medicina que abraçara desde sua formação (Pinheiro, 2000, p.50). Foi colaborador do programa radiofônico "A Voz da Homeopatia" a partir de 1939, publicando vários artigos em 1940 no periódico A Voz da Homeopatia, órgão de divulgação da Associação Paulista de Homeopatia nesse ano. Transferiu-se para Porto Alegre em dezembro de 1940, onde colaborou em jornais locais, como o Correio do Povo, o Diário de Notícias e, a partir de junho, o católico A Nação. Em 28 de junho de 1941 passou a ser responsável por um programa semanal na Rádio Farroupilha.

Atuou como clínico em Porto Alegre e, para ampliar a proposta homeopática, vinculouse ao desembargador Nésio de Almeida através da Farmácia Homeopática de Luiz G. Klein \& Cia., que patrocinou a publicação de sua obra Homeopatia: terapêutica positiva, em 1933, bem como auxiliou a propaganda desenvolvida por Castro (1933) no rádio e na imprensa. A apresentação do livro, assinada por Nésio de Almeida, se refere ao interesse da obra na divulgação dos princípios homeopáticos - o que é endossado por sua reedição, em 1944, como uma das obras da Biblioteca da Liga Homeopática. David Castro transferiu-se para o Rio de Janeiro em maio de 1955, onde continuou a atuar na área da homeopatia. Faleceu em 1980, tendo vários outros títulos publicados ao longo da sua carreira (Martins, 1971, s.d.).

O livro Homeopatia: terapêutica positiva reúne palestras curtas que defendiam a homeopatia das acusações recebidas nas décadas de 1920 e 1930. O discurso utilizado pelos homeopatas de formação foi analisado por Bertolli Filho, através de uma série de conferências realizadas pela Liga Homeopática Brasileira, em março de 1933, e publicadas no Rio de Janeiro. No conjunto de conferências analisadas, há algumas de David Castro, que foram também reproduzidas no livro publicado no Rio Grande do Sul. As conferências realizadas pela Liga em 1933 são emblemáticas do movimento de ideias do período. Buscava-se definir um perfil nacional-brasileiro; para tanto propunha-se uma identidade nacional com base em modelos abrangentes, integrais e que superassem os regionalismos. A intenção era atualizar o Brasil diante das rápidas mudanças no contexto internacional (Bertolli Filho, 1988, p.6). A campanha de divulgação da homeopatia, na qual se inseria a edição do livro de conferências (com tiragem de dois mil exemplares), tornava-se tarefa privilegiada de atuação social.

A análise de Bertolli Filho refere-se à forma e ao conteúdo dos textos publicados. Quanto à forma, verifica-se a tradição discursiva do fundador da doutrina, herdeiro do estilo romântico-conservador de escrita, caracterizando-se por discurso cujo tom dogmático é perseverante, apresentando verdades não por sua evidenciação, mas, sobretudo, por sua contraposição: defende-se a verdade ou o correto focando exatamente a situação oposta, apontando as falhas do objeto que se acredita falso ou incorreto. Apontam-se, aqui, apenas 
alguns pontos dos textos de homeopatas do período, analisados com grande propriedade por Bertolli Filho. Quanto ao conteúdo, ele monta uma 'sociologia dos temas', que analisa a homeopatia como ciência vinculada à perspectiva positivista, como prática especializada, como terapêutica (desconsiderando uma proposta moralizante), bem como o confronto com a alopatia, a ideia de conversão dos adeptos como evidência dos fundamentos da doutrina e o silêncio que os conferencistas mantiveram quanto à metafísica hahnemanniana, pois estavam todos imbuídos da necessidade de unificar uma proposta a fim de fazer frente aos ataques que a homeopatia sofria no período (Bertolli Filho, 1988, p.6-10).

A divergência entre alguns dos autores que participavam da proposta, entretanto, já era evidente desde 1918, nas disputas entre Alberto Seabra e Murtinho Nobre, que teriam ameaçado uma cisão. Aparentemente essa divergência se refere à proposta de uma homeopatia mais "espiritualizada", que se aproxima da perspectiva kardecista e que admite a "prática culta" do espiritismo, já que a maioria dos médiuns, quando servia de "aparelho" dos espíritos, receitava fórmulas homeopáticas (Bertolli Filho, 1988, p.10).

Na década de 1930 era comum a publicação de receituários homeopáticos destinados à consulta popular. Nesse período, duas obras eram muito conhecidas e utilizadas por leigos para o estabelecimento de autotratamento: Guia homeopático, do doutor Alberto Seabra, que chegou aos cem mil exemplares, e Guia homeopático das mães, do doutor Nery Gonçalves (Bertolli Filho, 1988, p.12). Tratava-se de mais uma estratégia de popularização da proposta homeopática, difundindo seus princípios de forma generalizada no nível corriqueiro de outros 'manuais populares' que serviam como obras de referência para diversas práticas de cura.

A obra de Alberto Seabra era distribuída nas farmácias, a partir do Laboratório de Homeopatia do Dr. Alberto Seabra S.A., fundado em 1911, em São Paulo, com um depósito no Rio de Janeiro e outro em Porto Alegre. Continha conselhos, sugestões culinárias, higiene infantil, informações sobre a homeopatia, guia para tratamento das moléstias mais comuns, patogenia de alguns medicamentos, específicos homeopáticos do doutor Seabra, produtos preparados no laboratório, tabela de preços das especialidades e de outras homeopatias. E destacava a possibilidade de serem feitos pedidos por correio (Seabra, 1920). Esse tipo de material aparentemente funcionou como uma continuidade dos almanaques de farmácia que surgiram no final do século XIX, quando a ciência era a palavra de ordem (Meyer, 2001, p.127) e os almanaques serviam como propaganda, informação e entretenimento. Essa similaridade, entretanto, provocou efeito contrário na divulgação da homeopatia, porque os médicos ridicularizavam a proposta, considerada muito popular e preocupada com a propaganda, pois os almanaques eram com frequência distribuídos por laboratórios que procuravam difundir seus compostos (propaganda considerada excelente negócio por quem investia nessa prática ${ }^{2}$.

Alberto Seabra é citado pelos autores que divulgam a proposta de Hahnemann como exemplo dos casos de conversão à homeopatia após a cura de um filho em 1908, tendo a medicação sido administrada pelos irmãos Manuel e Antônio Murtinho Nobre (com quem ele veio a ter divergências). Seabra formou-se na Faculdade de Medicina do Rio de Janeiro, em 1895, atuando em Sorocaba até 1897. Foi um dos iniciadores do Instituto Pasteur e um dos fundadores da Universidade de São Paulo, tido como médico de considerável reputação, 
chegando a exercer a vice-presidência da Sociedade de Medicina e Cirurgia. Após a conversão, estudou a obra de Hahnemann e passou a ser grande difusor dos princípios homeopáticos até seu falecimento, em 1934 (Pinheiro, 2000, p.43-44).

Além da estratégia de divulgação da homeopatia em livros populares, Seabra também publicou outra obra, procurando esclarecer suas posições a respeito da proposta homeopática, intitulada Esculápio na balança ou a superstição dos remédios (Seabra, 1943), cuja reedição foi autorizada por sua viúva, sendo o segundo volume da Biblioteca Homeopática da Liga Homeopática do Rio Grande do Sul. Positivista assumido, Seabra criticava duramente a proposta de evolução da medicina ao longo dos tempos, argumentando que os avanços da medicina têm limites estreitos para a cura dos pacientes. Procurava recuperar os princípios de Hipócrates como base para a homeopatia, princípios que teriam sido perdidos ao longo da história, bem como, aliás, o respeito ao célebre juramento. Também advogava a necessidade da ciência para a defesa dos princípios homeopáticos, mas a ciência em seu estádio positivo, com o atendimento dos princípios defendidos na perspectiva de Comte. Não fazia referência específica à necessidade de formação dos médicos, mas os princípios positivistas sugerem que a escolha dos profissionais da área médica se faria por indicação dos mais competentes pela população, quando estivesse plenamente desenvolvido o estádio positivo da organização das comunidades. Os profissionais mais qualificados seriam escolhidos pela atuação adequada junto à população.

Outra proposta, defendida por David Castro, argumentava a fundamental necessidade de formação acadêmica para os homeopatas, insistindo na discussão e cooperação com pessoas que tivessem estudado a doutrina, principalmente médicos de formação, condição indispensável para o exercício da homeopatia. Afirmava que ninguém podia ser homeopata sem antes ser médico e ter cursado todas as classes que constituem a base terapêutica. Considerava a homeopatia uma doutrina terapêutica dentro da medicina, com um curso extra de doutrina e terapêutica homeopática, de três árduos anos de estudo, como, segundo ele, era feito na época: "A homeopatia não é uma 'panaceia curadora'. ... É uma teoria, um método de cura, com suas leis e seus remédios, mas o seu conhecimento e sua aplicação implicam, antes de mais nada, o conhecimento da anatomia, da fisiologia, da biologia, da patologia, da física e química biológicas, da psicologia, da neurologia, da psiquiatria, o conhecimento, enfim, de tudo quanto constitui o estudo da medicina" (Castro, 1933, p.52).

Castro condenava os 'práticos' que supunham poder atender com base na utilização de um manual e afirmava a homeopatia como ciência difícil e árdua, cuja compreensão e aplicação demandariam formação médica e conhecimento profundo da doutrina homeopática. "Ninguém pode ser médico homeopata sem ser médico. E isso não é uma afirmação no sentido legal, mas no sentido científico, clínico e cultural" (Castro, 1933, p.50).

Em sua opinião, os práticos leigos contribuíram, em seu tempo, para a popularização da homeopatia como arte de cura, mas não como ciência e terapêutica. Os benefícios relativos, contudo, não compensavam os inconvenientes que os práticos representam para o progresso da homeopatia e de qualquer outra ciência ou atividade em que especialistas tenham que competir com leigos. Reconhecia a diferença entre os práticos desinteressados, que receitavam a homeopatia por amor ao próximo, por caridade e convicção, e aqueles movidos por interesse, que a receitavam por pagamento ou vinculados a algum laboratório. 
Sobre os 'desinteressados', dizia não fazer oposição sistemática, mas, como médico, tudo teria feito para conseguir que outros médicos e acadêmicos de medicina estudassem a homeopatia e aprendessem a aplicá-la. A liberdade profissional no Rio Grande do Sul seria responsável pela quantidade de práticos encontrados no estado, pois a terapêutica homeopática, aparentemente mais fácil e mais simples, teria sido a preferida pelos que decidiram aproveitar a liberdade profissional para fazer-se médicos. Destaca-se nessa obra especificamente a proposta relativa à defesa da homeopatia científica, mas, como bem analisou Bertolli Filho (1988), Castro aborda diversos outros temas na divulgação dos princípios de Hahnemann.

David Castro fez parte do grupo de homeopatas que assumiu como estratégia a defesa do discurso científico para aproximar médicos, adeptos e clientes. Utilizou esse discurso no contexto em que ele era o mais valorizado, procurando afastar as demais opções, leigas e práticas. Empenhava-se na divulgação da homeopatia como parte de um universo médico científico e técnico, cuja necessidade, nesse contexto, parecia imperiosa. Em atuação posterior continuou a advogar a causa da homeopatia como proposta científica. Depois de 1955, quando se transferiu para o Rio de Janeiro, foi livre-docente da Clínica Médica Homeopática da Escola de Medicina e Cirurgia do Rio de Janeiro em 1958, vice-presidente da Liga Homeopática Internacional a partir de 1961 e presidente da Associação Paulista de Homeopatia de 1961 a 1964 (Pinheiro, 2000, p.50).

Apesar dessas divergências, que os homeopatas procuravam não expressar, utilizam-se aqui para analisar sua forma de propaganda da homeopatia os argumentos desenvolvidos por David Castro divulgados no Boletim de Homeopatia da Liga Homeopática do Rio Grande do Sul. Durante o 3ํㅡㄹ Congresso Brasileiro de Homeopatia, realizado em São Paulo, em 1952, Castro apresentou os nove itens que constituem o programa de divulgação da homeopatia a ser defendido por todos os homeopatas e 'homeopatistas': (1) expansão territorial da homeopatia além de São Paulo, Rio de Janeiro e do Rio Grande do Sul; (2) elevação do prestígio e fortalecimento do Instituto Hahnemanniano como órgão controlador da homeopatia em todo o país; (3) criação de órgão popular de difusão da doutrina e dos preceitos com circulação em todo o país; (4) formação de novos médicos homeopatas e a consequente necessidade de cursos de pós-graduação, dentro do rigoroso controle teórico, sob orientação científica do Instituto Hahnemanniano; (5) criação de ligas ou sociedades leigas que trabalhassem pela difusão popular da homeopatia e pela criação de ambulatórios e dispensários, sobretudo independentes dos grandes laboratórios e farmácias homeopáticos, embora com seu apoio; (6) divulgação propriamente dita, mediante programas radiofônicos, colaboração em jornais leigos e especializados, conferências, participação em congressos etc.; (7) obtenção da obrigatoriedade da criação de clínicas homeopáticas nas autarquias e entidades de classe; (8) edição de livros homeopatas, científicos e de divulgação; (9) ampliação do intercâmbio internacional, pela importação de livros e revistas homeopatas.

Esse plano de atuação apoiava-se na crença na homeopatia como terapêutica do futuro, embora sua vitória ainda estivesse longe de ser vislumbrada, e ela nem sequer ainda ocupasse lugar na vanguarda dos métodos de cura utilizados pela humanidade. Um médico homeopata seria muito mais do que um médico, pois teria deveres com a doutrina que abraçou e que o instruiu, como também com a ciência e a humanidade. Sua proposta tinha como 
base a filosofia de que os homens deveriam buscar a perfeição, que consistia na supremacia das próprias virtudes e do altruísmo inerente a todos. Esses valores produziriam grandes obras quando informados por alguma doutrina sólida, como a hahnemanniana. Sugerindo organização e centralização como eixos da divulgação, defendia o Instituto Hahnemanniano como órgão a exercer essa congregação nacional (Castro, 1952, p.35-40).

Mediante as atividades da Liga Homeopática do Rio Grande do Sul tentou-se pôr em prática os elementos propostos por David Castro, elegendo-a como a organização que congregasse os esforços de divulgação da homeopatia na cidade de Porto Alegre, através do atendimento gratuito nos dispensários; que promovesse sua divulgação através de meios de comunicação diversos; que estimulasse o empenho de dar visibilidade à homeopatia através da organização de congressos e da inauguração das hermas homenageando homeopatas exemplares. O esforço realizado procurava atender aos princípios humanos enunciados, que permitia à homeopatia ser a sólida base doutrinária para a construção das grandes obras. Se esse é o discurso que os homeopatas procuraram construir por intermédio de suas instituições, nem sempre as atividades práticas foram pautadas pela agregação e unificação das propostas. No caso do Rio Grande do Sul, obtiveram grande visibilidade para suas atividades. No órgão de divulgação nacional, que segundo David Castro deveria ser o Instituto Hahnemanniano, a proposta é, entretanto, mais marcada pela dispersão e pela divergência. Apesar disso, alguns poucos homeopatas causaram grande rebuliço, indicando que as estratégias de divulgação tiveram alguma eficácia.

\section{Considerações finais}

A disputa por legitimidade estabeleceu, entre a medicina alopática e a homeopática, relações conflituosas e difíceis no início do século XX - a ponto de a versão oficial ter procurado eliminar a homeopatia como área concorrente, negando sua existência. $\mathrm{Na}$ dependência da aprovação formal de outros médicos, muitos receavam a adoção explícita da homeopatia temendo ser tachados de charlatães. Ainda assim, considera-se que as opções 'perdedoras' também devem ter sua voz resgatada pela historiografia, para que se possa entender até como certos preconceitos se formaram e estabeleceram.

A lógica dos discursos compõe-se como reação estratégica à desqualificação da proposta homeopática, ditada pelas condições históricas que permeavam as práticas médicas no decorrer das décadas de 1940 e 1950. Entretanto, apesar de a estratégia de valorizar a homeopatia como discurso científico ter sido adotada por vários autores, eles apresentavam diferenças em outros aspectos. Castro defendia a formação médica específica para os homeopatas, enquanto Seabra facilitava a divulgação de manuais que ampliavam a utilização da homeopatia por leigos, além de sua opção explícita pela perspectiva positivista. Muitos dos homeopatas que atuaram no Brasil adotaram propostas diversificadas em suas práticas, dependendo da formação e de como se aproximaram da perspectiva de Hahnemann. A unidade proposta por Castro nas décadas de 1940 e 1950 deve ser percebida como estratégia dos autores frente às dificuldades encontradas naquele contexto histórico. Suas ações para legitimação do discurso homeopático baseavam-se no discurso científico composto no período, procurando superar os regionalismos e oferecendo viabilidade nacional. 


\section{NOTAS}

${ }^{1}$ A descrição da organização da Liga Homeopática do Rio Grande do Sul foi apresentada no $10^{\circ}$ Encontro Estadual de História, realizado em Santa Maria (RS), em julho de 2010. Essa descrição é necessária para o entendimento da discussão acerca das estratégias elaboradas pelos homeopatas, no contexto político dos anos 1940, para divulgação de sua proposta e consolidação de sua inserção social, foco deste artigo.

${ }^{2}$ O proprietário do Laboratório Farmacêutico Daudt Oliveira \& Cia. Ltda., que lançou a pomada Boroborácica, o tônico A Saúde da Mulher e o xarope Bromil, considerava um importante elemento de propaganda do tônico e dos outros produtos o Almanaque d'A Saúde da Mulher, cujos dois milhões de exemplares eram distribuídos diretamente em setecentas localidades do Brasil (Daudt Filho, 2003, p.128).

\section{REFERÊNCIAS}

BERTOLLI FILHO, Claudio.

A doutrina homeopática no Brasil: os anos 30. Revista de Homeopatia, São Paulo, v.53, n.2, p.5-12. 1988.

BOLETIM...

Boletim de Homeopatia. Porto Alegre, n.184. 1977.

BOLETIM...

Boletim de Homeopatia. Porto Alegre, n.47-48. 1950.

BOLETIM...

Boletim de Homeopatia. Porto Alegre, n.39-40. 1949.

CASTRO, David.

A difusão da homeopatia. Boletim de Homeopatia, Porto Alegre, n.57-58, p.35-40. 1952.

CASTRO, David.

Homeopatia: terapêutica positiva. Porto Alegre: Farmácia Homeopática de Luiz G. Klein \& Cia. 1933.

DAUDT FILHO, João.

Memórias. 4.ed. Santa Maria: Editora

Universidade Federal de Santa Maria. 2003.

FEE.

Federação de Economia e Estatística. De província de São Pedro a estado do Rio Grande do Sul: censos do RS (1803-1950). Porto Alegre: Federação de Economia e Estatística. 1981.

FERRARETTO, Luiz Artur.

Rádio no Rio Grande do Sul (anos 20, 30 e 40): dos pioneiros às emissoras comerciais. Canoas: EdUlbra. 2002.

GERTZ, René. O aviador e o carroceiro: política, etnia e religião no Rio Grande do Sul dos anos 1920. Porto Alegre: EdPUCRS. 2002.
LUZ, Madel.

$A$ arte de curar versus a ciência das doença: história social da homeopatia no Brasil. São Paulo: Dynamis Editorial. 1996.

MARTINS, Souza (Org.).

Efemérides hahnemannianas: Estado do Rio Grande do Sul. Rio de Janeiro: Boletim de Homeopatia; Instituto Hahnemanniano do Brasil. 1971.

MARTINS, Souza.

Anotações datilografadas por Souza Martins. Rio de Janeiro: Arquivo Souza Martins. s.d.

MEIRELLES, Alberto Soares de.

Pequena história da homeopatia com suas repercussões na cidade do Rio de Janeiro, no período de 1886 a 1986. Revista Brasileira de Homeopatia, Rio de Janeiro, v.1, n.1, p.3-21. 1991.

MEYER, Marlyse.

Do almanak aos almanaques. São Paulo: Ateliê Editorial. 2001.

PINHEIRO, Décio.

Contribuição à história da homeopatia em São Paulo. Revista de Homeopatia, São Paulo, v.65, n.2, p.43-50. 2000.

RODRIGUES, Jaime; VASCONCELLOS, Maria da Penha Costa.

A guerra e as laranjas: uma palestra radiofônica sobre o valor alimentício das frutas nacionais (1940). História, Ciências, Saúde-Manguinhos, Rio de Janeiro, v.14, n.4, p.1401-1414. 2007.

SEABRA, Alberto.

Esculápio na balança ou a superstição dos remédios. Porto Alegre: Livraria Continente. 1943. 